\title{
GAMBARAN KETERATURAN MENGONTROL TEKANAN DARAH PADA PASIEN HIPERTENSI DI PUSKESMAS KEDURUS SURABAYA
}

\author{
Delly Amansyah Tohari*, Umdatus Soleha** \\ Fakultas Keperawatan dan Kebidanan \\ Universitas Nahdlatul Ulama Surabaya Jl. Smea 57 Surabaya \\ Email: umdatus@unusa.ac.id
}

\begin{abstract}
Overview of the regularity of blood pressure control in hypertensive patients Patient with hypertension in the PHC Kedurus obtained control blood pressure every 3 months diligently, and at several other patient are rarely control. Regularity in controlling blood pressure can prevent the recurrence of hypertension. The purpose of this study to determine the regularity Overview blood pressure control in hypertensive patient at the health center Kedurus Surabaya. The study used descriptive design. The population involved 83 peoples with hypertension one stadium in the PHC Kedurus Surabaya. Researh sample 69 taken use Probability sampling techniques of sampling with simple random sampling technique. Variable research is regularity control blood pressure in hypertensive patient collect data used observation sheet. The result showed that 69 respondents almost all $(85,5 \%)$ have a regular degree of regularity when their blood pressure checked. Results Chi-Square obtained, meaning the picture order to control blood pressure in hypertensive patients in PHC Kedurus Surabaya. Regular blood pressure control could prevent the recurrence of hypertension and lowers effectively. Patients are expected to take medication regularly to lower blood pressure.
\end{abstract}

\begin{abstract}
Abstrak: Gambaran keteraturan mengontrol tekanan darah pada pasien hipertensi di Puskesmas Kedurus Surabaya. Pasien penderita hipertensi di Puskesmas Kedurus didapatkan rajin mengontrol tekanan darah setiap 3 bulan, dan beberapa penderita lainnya terdapat jarang mengontrol akibatnya tidak mampu mencegah kambuhnya hipertensi. Tujuan penelitian ini untuk mengetahui Gambaran keteraturan mengontrol tekanan darah pada pasien hipertensi di Puskesmas Kedurus Surabaya. Penelitian ini menggunakan desain Deskriptif. Populasi penelitian pasien hipertensi stadium 1 yang berada di Puskesmas Kedurus Surabaya sebesar 83 orang. Sampel penelitian sebesar 69 responden diambil dengan teknik Probability sampling dengan teknik simple random sampling. Variabel independen Keteraturan mengontrol tekanan darah. Instrumen pengumpulan data menggunakan lembar observasi. Hasil penelitian didapatkan bahwa 69 responden hampir semua $(85,5 \%)$ memiliki tingkat keteraturan yang teratur dan sebesar $(14,5 \%)$ memiliki tingkat keteraturan tidak teratur pada saat memeriksa tekanan darahnya. Kontrol tekanan darah secara teratur dapat mencegah kambuhnya hipertensi dan menurunkan secara efektif. Pasien diharapkan mengkonsumsi obat secara teratur untuk menurunkan tekanan darah,
\end{abstract}

Kata Kunci: Hipertensi, Tekanan darah, Keteraturan 


\section{PENDAHULUAN}

Hipertensi merupakan penyakit yang lebih dikenal sebagai peningkatan tekanan darah yang mempunyai faktor resiko utama dari perkembangan penyakit jantung dan stroke. Penyakit hipertensi ini juga disebut sebagai " the silent diseases" karena gejala yang ditimbulkan tidak dapat dilihat dari luar. Pada umumnya hipertensi menyerang pada orang lanjut usia. Kini banyak ditemukan penderita hipertensi berusia dewasa awal, karena terdapat beberapa faktor yang mempengaruhi. Salah satu penyebabnya gaya hidup dan pola makan. Gaya hidup yang bertentangan dengan kesehatan menjadi pemicu munculnya hipertensi yaitu kebiasaan merokok, mengkonsumsi kopi berlebih, terlalu sering makan junk food yang mengandung banyak garam dan kurangnya berolahraga (Dalimartha, 2008).

Fenomena yang ditemukan di Puskemas, beberapa penderita hipertensi didapatkan tidak teratur dalam mengontrol tekanan darahnya di puskesmas. Beberapa dari mereka rajin mengontrol tekanan darah setiap 1 bulan, beberapa penderita lainnya jarang kontrol disebabkan kesibukan aktivitasnya. Alasan penderita jarang memeriksakan tekanan darahnya karena kesibukan aktifitas setiap hari, tidak merasa ada gangguan kesehatan pada tubuhnya dan beberapa takut ditemukan suatu penyakitnya. Dari beberapa penderita hipertensi, beberapa dari mereka tidak mengerti secara pasti pengertian, penyebab dari penyakit itu muncul, terkadang dari mereka menyepelekan bahaya penyakit hipertensi.

Beberapa faktor yang mempengaruhi ketidakteraturan seseorang dalam mengontrol tekanan darah antara lain mereka terlalu sibuk terhadap pekerjaan atau kegiatan sehari-harinya dan juga masyarakat masih menganggap bahwa penyakit hipertensi itu adalah penyakit yang tidak membahayakan.
Ketidakteraturan penderita hipertensi untuk mengontrol dan juga meminum obat anti hipertensi dapat menyebabkan komplikasi pada penyakit hipertensi sehingga dapat menyebabkan kerusakan organ meliputi otak, karena hipertensi yang tidak terkontrol dapat meningkatkan resiko stroke kemudian kerusakan pada jantung (Mutaqqin, 2009).

Menurut WHO ((World Health Organization) tahun 2011 menunjukkan di seluruh dunia sekitar 972 juta orang atau $26,4 \%$ penduduk bumi menghidap hipertensi dengan perbandian 26,65 pria dan $26,1 \%$ wanita. Hasil riset kesehatan dasar (RISKESDAS) pada tahun 2013 menunjukkan tingginya prevalensi hipertensi di Indonesia yaitu 25,8\% dan hanya sekitar $9,5 \%$ penduduk yang sudah mengetahui memiliki hipertensi. Menurut hasil riset dinas kesehatan Provinsi Jawa Timur tahun 2013 mempunyai prevalensi sebesar 37,4\%.

Menurut Survei Terpadu Penyakit atau disingkat STP Puskesmas di Jatim tahun 2010, sejumlah daerah di Jatim yang paling banyak menyumbang pasien penderita hipertensi Kabupaten Malang, jumlah penderita 31.789 orang. Disusul Kota Surabaya peringkat ke -2 sejumlah 28.970 penderita, Madura peringkat ke-3 sebanyak 28.955 penderita. Secara keseluruhan jumlah penderita hipertensi di Jatim mencapai 275.000 orang. Berdasarkan data awal yang diperoleh dari data kesehatan Pukesmas Kedurus, Kota Surabaya pada bulan Januari 2015 jumlah penderita hipertensi sudah mencapai $60 \%$ kasus dari jumlah pasien dipuskesmas

Berdasarkan hasil studi awal di Puskesmas Kedurus, Kota Surabaya yang telah dilakukan peneliti bulan Januari 2015 terdapat 460 orang menderita hipertensi. Hipertensi dapat dikontrol dengan cara mengontrol kebiasaan buruk yang beresiko hipertensi dan rajin memeriksakan tekanan darahnya setiap bulan. Dengan kita mengetahui hasil 
tekanan darah maka kita dapat mengontrol sehingga tidak sampai muncul gejala penyakit komplikasi. Hasil survei yang telah dilakukan terhadap 460 pasien penderita hipertensi di Puskesmas Kedurus didapatkan hasil 340 orang rajin mengontrolkan tekanan darahnya sehingga mengetahui cara mengatasi hipertensinya agar kembali normal dan 120 orang lainnya jarang sekali mengontrol tekanan darahnya kecuali sudah merasakan gejala yang muncul akibat dari hipertensi. Didapatkan pula 83 orang menderita hipertensi stadium satu di Puskesmas Kedurus Surabaya.

Upaya untuk meningkatkan kepatuhan masyakat untuk selalu mengontrol tekanan darahnya salah satunya adalah dengan kombinasi seperti edukasi, modifikasi sikap dan sistem yang mendukung dengan membantu pasien memodifikasi pola hidupnya selain itu juga keluaraga pasien harus selalu mengingatkan pada pasien untuk selalu mengontrol tekanan darahnya minimal 1 kali sebulan agar pasien dapat mengotrol penyakitnya supaya tidak menjadi komplikasi (Mutaqqin, 2009).

Berdasarkan semua yang telah disampaikan di atas, penulis ingin meneliti gambaran keteraturan mengontrol tekanan darah pada pasien hipertensi di Puskesmas Kedurus Surabaya.

\section{METODE}

Rancangan atau desain penelitian yang digunakan adalah deskriptif. Populasi dalam penelitian ini adalah seluruh penderita hipertensi stadium 1 di Puskesmas Kedurus Surabaya dengan jumlah 83 orang pada bulan Juli 2015 . Sampel dalam penelitian ini adalah sebagian orang yang berada di Puskesmas Kedurus Surabaya dengan kriteria penderita hipertensi stadium 1 yang rajin mengontrol dan tidak rajin mengontrol tekanan darahnya. Besar
Sampel adalah 69 responden. Cara pengambilan sampel menggunakan purposive sampling. Istrumen penelitian berupa lembar observasi.

\section{HASIL DAN PEMBAHASAN \\ a. Hasil}

Hasil penelitian menunjukkan bahwa 69 responden hampir semua $(85,5 \%)$ memiliki tingkat keteraturan yang teratur pada saat memeriksakan hipertensinya. Sebagaimana kita ketahui semakin tinggi pendidikan seseorang maka semakin luas pula pengetahuannya. Dengan banyaknya pengetahuan apalagi mengenai kesehatan, maka harusnya setiap penderita dapat mengetahui penyebab, cara mengobati, dan melindungi diri dari penyakit tersebut. Kita ketahui semua bahwa mencegah lebih baik daripada mengobati.

\section{b. Pembahasan}

Menurut Hoetomo (2008) keteraturan adalah kesamaan keadaan, kegiatan, atau proses yang terjadi beberapa kali atau lebih dalam suatu keadaan atau hal yang teratur. Hampir seluruhnyan responden (89\%) mempunyai hipertensi melakukan pemeriksaan secara teratur dalam satu tahun terakhir dengan latar belakang tingkat pendidikan Tinggi.

Adanya keteraturan kontrol disebabkan adanya pengetahuan mengenai penyakit hipertensi yang kapan saja bisa kambuh. Pada penderita yang berpendidikan tinggi lebih memiliki kemauan untuk mengontrol kan tekanan darahnya agar mengetahui adanya perubahan pada tekanan darahnya meski belum ada keluhan yang muncul mengenai hipertensinya. Gambaran keteraturan mengontrol dengan pendidikan penderita tidak selalu ada hubungan, namun ada hampir semua responden ada kaitan satu sama lain.

Menurut Nursalam (2008) menyatakan bahwa makin tinggi tingkat 
pendidikan seseorang, makin mudah menerima informasi sehingga banyak pula pengetahuan yang dimiliki, sebaliknya pendidikan yang rendah akan menghambat perkembangan sikap seseorang terhadap nilai-nilai yang diperkenalkan .

\section{Simpulan}

Berdasarkan hasil penelitian pada responden (penderita hipertensi) di Puskesmas Kedurus Surabaya mengenai Keteraturan Mengontrol tekanan darah pada pasien hipertensi stadium 1 dapat disimpulkan bahwa responmden (pasien hiepertensi) teratur dalam mengontrolkan tekanan darahnya.

\section{DAFTAR PUSTAKA}

Aaronson, Ward. (2008). At a Glance Sistem Kardiovaskuler. Edisi ketiga. Jakarta:Erlangga

Arikunto, Suharsini. (2010). Prosedur Penelitian Suatu Pendektan Praktik. Jakarta: Rineka Cipta

Beevers, DG. (2002). Seri Kesehatan Bimbingan Dokter pada Tekanan Darah. Jakarta: PT. Dian Rakyat

Black, J. M \& Hawks, J. N (Eds). (2005). Medical Surgical Nursing. Volume 2. 7 Edition China: Elsivier Saunders

Dalimartha, Purnama, Sutarina dkk. (2008). Care Your Self Hipertensi. Jakarta: Penebar Plus ${ }^{+}$

Dr. Yekti \& Ari Wulandari. (2011) Cara Jitu Mengatasi Hipertensi. Jakarta: Andi Publisher

Elsanti, Salma. 2009.Panduan Hidup Sehat Bebas Kolesterol, Stroke, Hipertensi \&

SeranganJantung. Yogyakarta : Araska.

Gray, Dawkins, Morgan dkk. (2005). Lecture Notes: Kardiologi. Edisi keempat.Jakarta: Erlangga

Hanns Peter, W. (2008). Hipertensi, PT Bhuana Ilmu Populer, Gramedia, Jakarta.
Hart, Fahey, Savage. (2009). Tanya Jawab Seputar Tekanan Darah Tinggi. Edisi 2.Jakarta: Arcan

L. Stanley. (2007). Buku Ajar Patologi Robbins,. Edisi7. Jakarta: EGC

Marliani L, dkk. (2007). 100 Question \& Answers Hipertensi. Jakarta : PT Elex Media Komputindo, Gramedia.

Mickey Stanley. (2007) Buku Ajar Keperawatan Gerontik, Edisi 2. Jakarta: Egc

Muttaqin, Arif. (2009). Pengantar Asuhan Keperawatan Klien dengan Gangguan Sistem Kardiovasculer. Jakarta: Salemba Medika

Nursalam. (2009) Pendidikan Dalam Keperawatan, Jakarta: Salemba Medika

Rohaendi. (2003).Hipertensi Dan Faktor Resiko, Http://Rohaendi.Com/2008_06 01 Archive.Html Diakses Tanggal 3 Februari 2012.

Rohaendi. (2008). Hipertensi. Diambil tanggal 16 September 2009 darihttp://dimasmis.blogspot.com/h $\underline{\mathrm{tml}}$

Santoso, Fredy. Diet Pencegah Hipertensi. (2009). Diakses Tanggal 15 September 2009.

Soekidjo Notoatmodjo. (2007) Metodologi Penelitian Kesehatan. Jakarta: Rineka Cipta

Soekidjo Notoatmodjo. (2003) Promosi Kesehatan Dan Perilaku Kesehatan. Jakarta: Rineka Cipta 